Chromatographic separation methods of all kinds-paper, column, and gas chromatography-have made a tremendous impact in this field, as they have in all other fields of analytical and preparative chemistry. Used in combination with various methods for determining the isotope content of tracers, they dominate the field. For determination of ${ }^{14} \mathrm{C}$ in the form of ${ }^{14} \mathrm{CO}_{2}$ the low background anticoincidence counter has found

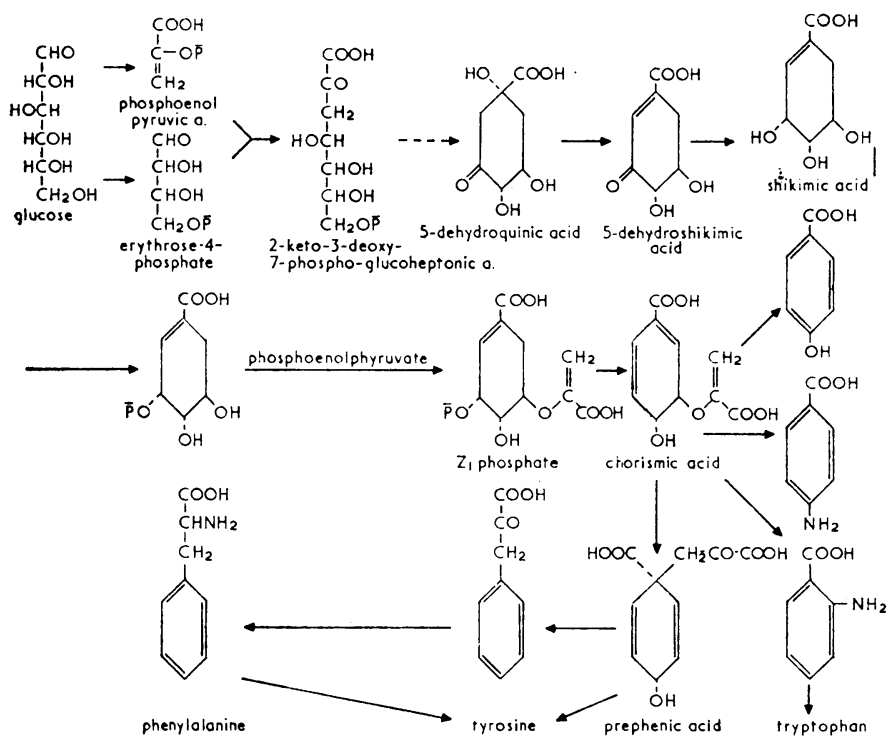

Fig. 23.-Biosynthesis of aromatic ring system.

wide application, but is rivalled by the considerably more costly scintillation counter which is suitable for $\beta$ as well as for $\gamma$ radiation, and therefore allows the determination of tritium, iodine, etc., in addition to ${ }^{14} \mathrm{C}$. It has the great additional advantage that it allows the determination of radioactivity directly in fractions coming from column chromatography, without first having to dry aliquots or to combust aliquots to $\mathrm{CO}_{2}$.

The chromatographic as well as the isotope-determination methods have been automated to a large degree. For the study of protein biosynthesis and similar problems the automatic amino-acid analyser has become an indispensable tool, which allows not only the neat separation of complex mixtures of amino-acids and their individual quantitative determination but also simultaneously the determination of their specific activity. Heavy isotopes are also extensively used in studies of metabolic pathways and the mechanism of action of the enzymes involved, particularly ${ }^{18} \mathrm{O}$ and ${ }^{15} \mathrm{~N}$, but also ${ }^{2} \mathrm{H}$. For the quantitative determination of the former mass spectrometric methods are used.

Looking back from our present position on the achievements attained in the field of metabolic pathways in the course of only thirty years, the progress is certainly impressive. However, despite all this progress, we are still as far away as ever from our final goal, to understand the biochemical functioning of the cell.

It is true we have discovered a great number of new biochemical reactions and reaction sequences, but it is surprising how little we know about their significance in the living cell, their relation to the specific functions in a particular cell kind, and the way in which the various reaction rates are regulated and interdependent. Yet these are problems of the very greatest importance, theoretical as well as practical, for all fields of biology, and not least for medicine-for metabolic disorders are caused by changes in metabolic reaction rates.

This brings me to the discussion of a field of research in which we are actively engaged at present and which will form one of the main topics of research in the newly constituted Metabolic Reactions Research Unit of the Medical Research Council, to be housed in our new Biochemistry Department: the mode of action of hormones.

[The conclusion of this Inaugural Lecture will be published in next week's issue.]

\title{
Primula Dermatitis
}

\author{
ARTHUR ROOK,* M.D., F.R.C.P. ; HAROLD T. H. WILSON, † M.D., F.R.C.P.
}

Brit. med. 7., 1965, 1, 220-222

Most doctors and many gardeners know that primulas may cause dermatitis, but general practitioners are often unfamiliar with the pattern of the rash produced. It was felt, therefore, that a clinical description would be helpful.

\section{The Primulaceae}

The primula family comprises some 22 genera and 600 species. The genera include Primula, Androsace, Soldanella, Lysimachia, Glaux, Anagallis, and Cyclamen.

The genus Primula contains over 200 species, including the common primrose and the cowslip. Those most commonly grown as house-plants are $P$. obconica (Fig. 1) and $P$. malacoides. $P$. sinensis is retailed in smaller quantities, while $P$. kewensis, $P$. floribunda, $P$. denticulata, and $P$. mollis

- Dermatologist, Addenbrooke's Hospital, Cambridge. Dermatologist, Addenbrooke's Hospital, Cambridge.
t Dermatologist, Central Middlesex and Royal Northern Hospitals,
London. also appear in florists' shops from time to time. With very rare exceptions only $P$. obconica causes dermatitis.

\section{Historical}

P. obconica (Fig. 1) was introduced to Britain from China in 1880 and rapidly became established as a popular greenhouse plant throughout Europe and the United States. The first accounts incriminating this plant as a cause of dermatitis were published in American horticultural journals and were received sceptically in England. However, reports of similar experiences in this country soon followed; one indignant gardener vigorously condemned "this vegetable viper." A year or two later reports began to appear in the medical journals, first in America and soon after in Britain (Sym, 1890 ; Clarke, 1890 ; Ferguson, 1890). So numerous were the reports that it was predicted (Cooper, 1899) that such a poisonous plant would be grown less and less frequently; but this prophecy 
has not been fulfilled, although this primula remains the commonest cause of plant dermatitis in this country (Rook, 1961).

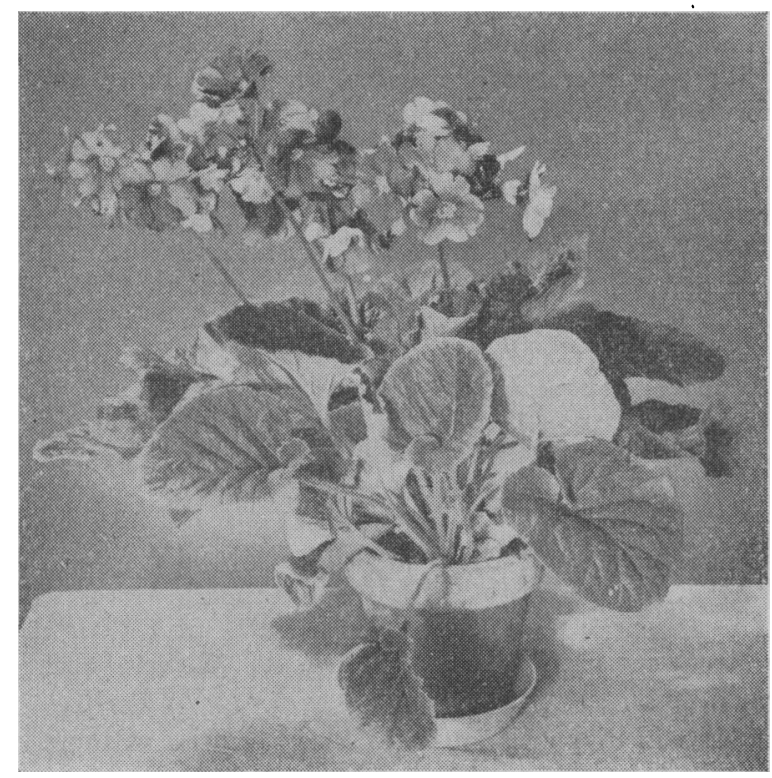

FIG. 1.-Primula obconica.

In Germany anxiety about primula dermatitis was voiced in a question on the subject in the Reichstag; and in the United States cases were sufficiently numerous for a report by Foerster (1910) to be based on personal experience of 40 to 50 patients. These statistics are a measure of the plant's popularity, for most people are able to handle the leaves of the primula with impunity ; and Shelmire (1939), who found an incidence of $8 \%$ among florists, was unable to discover a single case among 251 students tested against the leaves. Low (1924) was able to sensitize himself and his brother to $P$. obconica but failed to sensitize six other subjects.

\section{Clinical Features}

There were 25 patients in the series-24 females and 1 male. The age at which sensitivity began (Fig. 2) ranged from 15 to 79 , with an average of 51.6 years. The length of history before a diagnosis was made varied from 2 weeks to 10 years, with an average of 17.27 months. The sites principally involved (see Table) were the face, particularly round the mouth and on the eyelids, which were often red and swollen, the neck, arms, and hands. Rarely, patches occurred on the ears, thighs, buttocks,

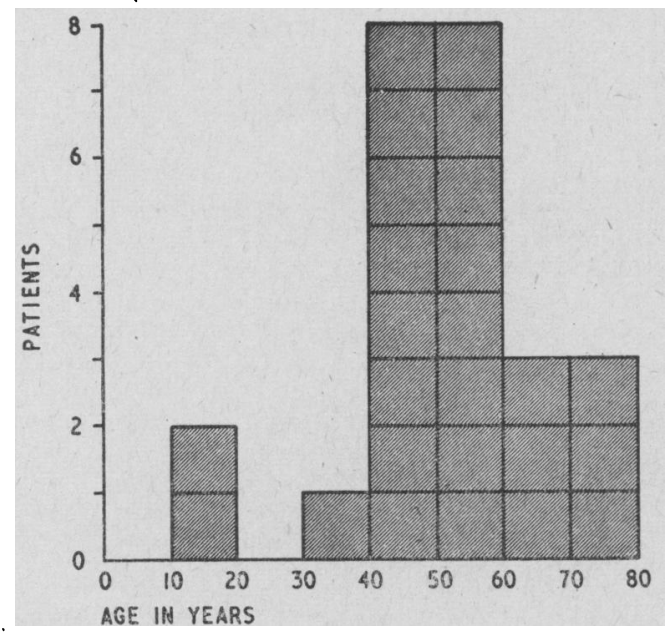

FIG. 2.-Age at onset of sensitivity to primula. Average age 51.6 years, range $15-79$ years. or ankles. The affected areas itched, burned, and appeared red, often oedematous, and frequently blistered. A distinctive pattern was often seen, particularly on the arms and forearms, consisting of blotches and linear streaks (Fig. 3). This appearance is very characteristic of plant dermatitis, and in this country is nearly always due to contact with a primula.

\begin{tabular}{|c|c|c|c|c|c|c|c|c|}
\hline \multicolumn{9}{|c|}{ Site Affected by Primula Dermatitis } \\
\hline \multicolumn{2}{|c|}{ Sites Affected } & \multirow{2}{*}{$\begin{array}{c}\text { Total } \\
13 \\
16 \\
14 \\
1 \\
12\end{array}$} & \multirow{2}{*}{$\begin{array}{r}\% \\
52 \\
64 \\
56 \\
4 \\
48\end{array}$} & \multicolumn{3}{|c|}{ Sites Affected } & \multirow{2}{*}{$\begin{array}{c}\text { Total } \\
9 \\
14 \\
1 \\
2 \\
1\end{array}$} & \multirow{2}{*}{$\begin{array}{r}\% \\
36 \\
56 \\
4 \\
8 \\
4\end{array}$} \\
\hline 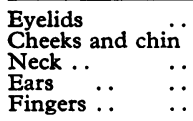 & $\begin{array}{l}\cdots \\
\because \\
\therefore \\
\therefore\end{array}$ & & & $\begin{array}{l}\text { Hands } \\
\text { Arms } \\
\text { Ankles } \\
\text { Thighs a } \\
\text { Tongue }\end{array}$ & $\begin{array}{c}. . \\
\because \\
\because \\
\text { and buttocks }\end{array}$ & $\begin{array}{l}\ldots \\
\because \\
\because\end{array}$ & & \\
\hline
\end{tabular}

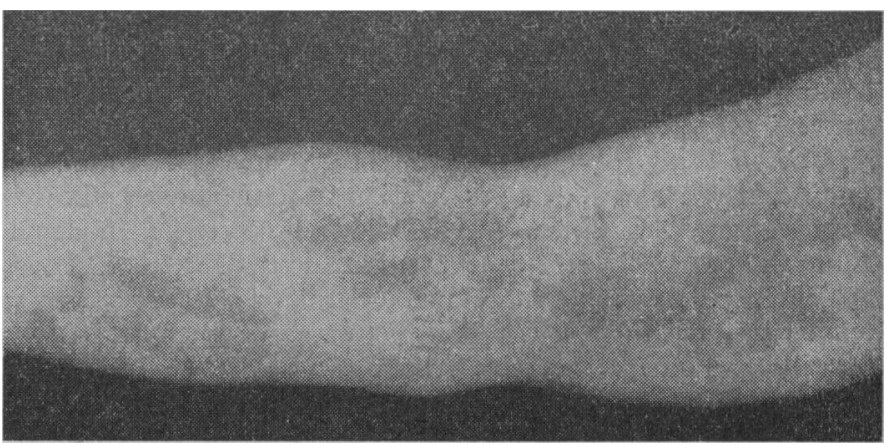

FIG. 3.-Linear pattern on arms and forearms.

On the sides of the fingers quite large blisters sometimes formed after the patient had pulled dead leaves off the plant (Fig. 4). Mucosal lesions were rare, but one patient complained of soreness of the lips and tongue, while another suffered not only from an extensive rash but from pyrexia, coryza, and conjunctivitis as a result of contact with a plant.

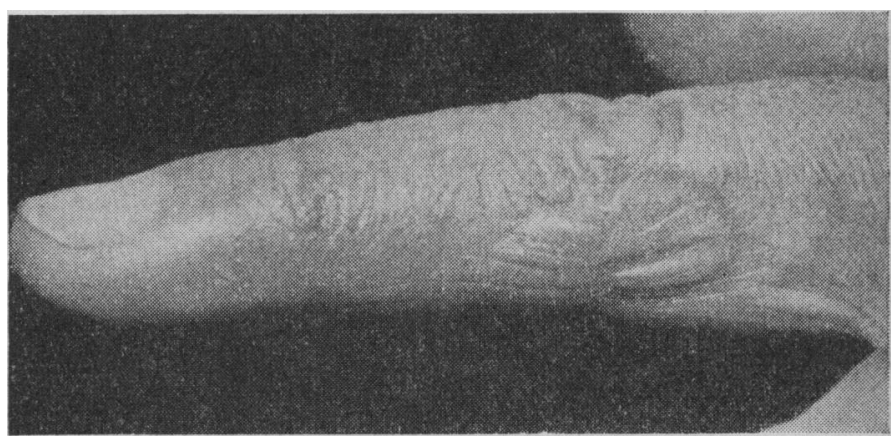

FIG. 4.-Blister on side of finger after handling leaves.

Less easy to recognize was the occasional mild case in which the only sign of primula sensitivity consisted in a single transient itching red patch, usually on the chin or the side of the neck, or recurrent irritation, redness, and swelling of the eyelids.

In severe cases, which may occur when the diagnosis is overlooked and the patient continues to handle the plants, the eruption may become very extensive and the face grossly oedematous, and fever and constitutional symptoms may develop. In one of our patients-not included in the present series-an attack of erythema multiforme complicated the already widespread dermatitis.

\section{Patch Tests}

Patients were tested against a piece approximately $1 \mathrm{~cm}$. square cut from a leaf of their own primula. Tests were performed on the back and read after 48 hours, and, when practicable, after five to seven days. All patients gave positive reactions, most 
of these being strongly positive and consisting of erythema, oedema, and small vesicles. One mild case gave a delayed positive reaction which appeared after seven days. Tests against the petals were equally positive, and reactions were also given to leaves which had been picked when growing strongly and dried for several months. As expected, these reactions were not quite so strong as those given by fresh leaves. Tests with leaves allowed to wither on the plant sometimes gave falsenegative reactions.

Where several tests were made, extreme caution was necessary in handling the leaves of the plant. These were picked up with forceps, which were afterwards washed. Unless this precaution was taken juice from the leaf was transferred by the fingers to other test substances. In primula-sensitive patients this would result in a strongly positive reaction to $P$. obconica being followed by false-positive reactions due to contamination of subsequent tests. Nineteen patients were also tested against other primulas. Of 233 tests carried out with 15 different species, 33 gave positive and 13 doubtful reactions, the remainder being negative. The results are interesting and significant when considered in relation to the botanical affinities of the species concerned, and will later be reported in detail. From the practical point of view it may be noted that there was no evidence that the individual allergic to $P$. obconica is regularly or even frequently allergic to any other species. With four exceptions the positive reactions were given by species rarely encountered in British gardens and belonging to the Cortusoides section of the genus Primula, some of which are known to be direct irritants.

\section{Discussion}

$P$. obconica owes its popularity to the beauty of its flowers, the length of its flowering season, and its capacity to withstand the uncertain conditions of the parlour table or the kitchen window-sill and even to survive periods of relative neglect. In most of our cases the parlour primula was the offender and the victims were the middle-aged or elderly women who tended it. However, the plant is also popular with the increasing band of amateur gardeners who own a small greenhouse, and we have recently often identified it in the troughs of plants with which it is fashionable to decorate the entrance halls and corridors of offices, shops-and hospitals. The population potentially at risk is therefore large, and it has become increasingly important for the doctor to suspect the diagnosis on the clinical picture. The horticulturists and florists who supply the constant demand for the plants have very often themselves become sensitized but seldom attend hospital, for they are fully aware of the diagnosis.

It is important to emphasize that our patch-test findings have confirmed that for all practical purposes only $P$. obconica causes dermatitis. The other species frequently grown for home decoration are $P$. malacoides and $P$. sinensis. $P$. malacoides has never been proved to cause dermatitis and $P$. sinensis has done so very rarely. There are reports in the literature incriminating other species. Some of these reports must be rejected, as the clinical diagnosis was not confirmed by patchtesting. The remaining reports concern species which are unlikely to be encountered in Britain outside the larger botanic gardens.

The sensitizing chemical in $P$. obconica has the empirical formula $\mathrm{C}_{14} \mathrm{H}_{18} \mathrm{O}_{3}$ or $\mathrm{C}_{14} \mathrm{H}_{20} \mathrm{O}_{3}$ (Bloch and Karrer, 1927). It can be isolated in crystalline form from ether extracts of the plant, and has been named primin. It is strongly unsaturated, but the structural formula is unknown. Primin is present throughout the leaves, stems, and flower, but is found in greatest quantity in the small glandular hairs which cover the leaves and stem. It is because the sensitizing agent is so accessibly situated that the skin can be contaminated by the most casual contact that the very distinctive pattern of dermatitis is produced. Among plants native to or cultivated in Britain this feature is peculiar to $P$. obconica.

The streaky and rectilinear plaques of erythema and oedema, sometimes vesicular, should suggest the diagnosis. Some plants, notably milfoil (Achillea millefolium), some of the buttercups (Ranunculaceae), and Brassica nigra and other mustards contain substances which are directly irritating to the skin, and these common weeds may provoke blisters, which are sometimes linear, when they are firmly crushed on the skin; but the history will help the diagnosis, and the average housewife is not at risk. Some other plants contain chemicals which photosensitize and provoke blisters if the skin be exposed to sunlight after the plants have been crushed against it. The lesions are often irregularly streaky, but are usually on the legs or trunk, and hikers and bathers rather than housewives are at risk. Plants other than $P$. obconica which produce an allergic dermatitis seldom do so except in those who are exposed in the course of their occupations or hobbies to close and repeated contact, for the sensitizing chemicals are not, as in the primula, on the outer surface of the plant. The clinical features of the resulting dermatitis are usually very different (Rook, 1962). The few exceptions are, in our experience, of little practical importance and account for less than $1 \%$ of plant dermatitis seen in hospital practice in England.

Problems in diagnosis are most likely to arise in those cases of primula dermatitis in which the eruption is confined to the face. Recurrent swelling and redness of the eyelids can be produced by a variety of other domestic sensitizing agents. It is therefore essential that a suspected diagnosis should always be confirmed by patch-testing with a primula leaf, and this simple and reliable test should be carried out in all cases, whether clinically typical or not.

When the diagnosis has been confirmed the housewife must part with her primula. The degree of sensitivity can be very high, and it is not sufficient merely to try to avoid contact with a plant which remains in the room. If the patient is a horticulturist who cannot delegate the handling of this species to a non-sensitized employee, he must be advised to abandon $P$. obconica and grow $P$. malacoides or $P$. sinensis. Since $P$. obconica is regarded as the most profitable of these species, being the most popular, it would obviously be reprehensible to give such advice to a patient in whom the diagnosis had not been established beyond doubt by patch-testing.

\section{Summary}

Twenty-five examples of primula dermatitis are described.

Typical cases have a characteristic streaky rash. Mild ones may present a few small red itching patches, usually on the face or neck. Sensitivity to Primula obconica is common; other primulas rarely sensitize.

Acknowledgments are due to Mr. J. L. Gilmour, Director of the Cambridge Botanic Gardens, and Mr. W. G. McKenzie, Curator of the Chelsea Physic Gardens, who supplied us with leaves; to Professor C. D. Calnan and the consultant staff at St. John's Hospital for Diseases of the Skin, London, who allowed one of us to patch-test his cases ; and to the Curator of Kew Gardens, who supplied some of the details about primulas.

REFERENCES

Bloch, B., and Karrer, P. (1927). Beibl. Vischr. Naturforsch. Ges., 72, 13.

Clarke, F. H. (1890). Brit. med. f., 2, 78 '́.

Cooper, B. (1899). Ibid., 2, 1543.

Ferguson, J. (1890). Ibid., 2, 954.

Foerster, O. H. (1910). f. Amer. med. Ass., 55, 642.

Low, R. C. (1924). Anaphylaxis and Sensitization, with Special Reference to the Skin and its Diseases, p. 175. Green, Edinburgh.

ence to the Skin and its Diseases, p.
Rook, A. (1961). Brit. F. Derm., 73, 283.

(1962). Practitioner, 188, 627.

Shelmire, B. (1939). f. Amer. med. Ass., 113, 1085.

Sym, A. C. (1890). Brit. med. F., 2, 686. 